\title{
Erratum to: Physical activity attenuates the mid-adolescent peak in insulin resistance but by late adolescence the effect is lost: a longitudinal study with annual measures from 9-16 years (EarlyBird 66)
}

\author{
Brad S. Metcalf ${ }^{1,2} \cdot$ Joanne Hosking $^{3} \cdot$ William E. Henley ${ }^{1}$ - Alison N. Jeffery ${ }^{3}$.
} Mohammod Mostazir ${ }^{4}$ Linda D. Voss ${ }^{3} \cdot$ Terence J. Wilkin $^{1}$

Published online: 10 September 2015

(C) Springer-Verlag Berlin Heidelberg 2015

Erratum to: Diabetologia

DOI 10.1007/s00125-015-3714-5

Unfortunately, the affiliation for Mohammod Mostazir was incorrect in this paper. His correct affiliation is listed below.

The online version of the original article can be found at http://dx.doi.org/ 10.1007/s00125-015-3714-5.

Brad S. Metcalf

b.metcalf@exeter.ac.uk

1 Institute of Health Research, University of Exeter Medical School, Exeter, UK

2 Sport and Health Sciences, College of Life and Environmental Sciences, University of Exeter, St Luke's Campus, Heavitree Road, Exeter EX1 2LU, UK

3 Department of Endocrinology and Metabolism, Plymouth University Peninsula Schools of Medicine and Dentistry, Plymouth, UK

4 Wellcome Trust Biomedical Informatics Hub, College of Life and Environmental Sciences (CLES), University of Exeter, Exeter, UK 